\title{
Association between ADD1 Gly460Trp Polymorphism and Essential Hypertension in Han Chinese
}


Zhang $^{1 *}$

${ }^{1}$ Department of Preventive Medicine and Zhejiang Provincial Key Laboratory of Pathophysiology, School of Medicine, Ningbo University, Ningbo, Zhejiang, PR China

${ }^{2}$ Bank of Blood Products, Ningbo Blood Center, Ningbo, Zhejiang, PR China

${ }^{3}$ Clinical laboratory, The Seventh Hospital of Ningbo, Ningbo, Zhejiang, PR China

\begin{abstract}
Background: The $A D D 1$ Gly460Trp polymorphism has been linked to essential hypertension (EH) in multiple populations, but the results were inconsistent. The goal of our study is to investigate the contribution of ADD1 Gly460Trp polymorphism and environmental factors to the risk of $\mathrm{EH}$.

Methods: We conducted a case-control study including 1020 hypertensive cases and 1020 controls, and the gender and age were well matched between hypertensive and control groups. Blood samples and participants information were also collected. Using the melting temperature shift technology, the ADD1 Gly460Trp polymorphism was genotyped among all subjects. Multifactor dimensionality reduction (MDR) was used to identify the interactions among the $A D D 1$ Gly460Trp polymorphism and the nongenetic factors.

Results: Our results showed that body mass index (BMI), total cholesterol, triglycerides, and drinking were significantly associated with $\mathrm{EH}(P<0.05)$. In addition, the Gly460Trp polymorphism was found significantly associated with hypertension at allelic level $(P<0.01 ; \mathrm{OR}=0.85 ; 95 \% \mathrm{Cl}=0.75-0.96)$. A breakdown association analysis by gender showed the Gly460Trp polymorphism was associated with $\mathrm{EH}$ only in female $(P<0.01 ; \mathrm{OR}=0.79 ; 95 \% \mathrm{Cl}=0.68-0.92)$. MDR analysis indicated that there was an interaction among BMI, high density lipoprotein, drinking, and rs4961 involved in the risk of $\mathrm{EH}$.
\end{abstract}

Conclusion: The present study indicated the Gly460Trp polymorphism was associated with EH in female Han Chinese, which might contribute to $\mathrm{EH}$ via interactions with non-genetic factors.

Keywords: Essential hypertension; ADD1; Polymorphism; Interaction

Abbreviation: EH: Essential Hypertension; ADD1: $\boldsymbol{\alpha}$-adducin; TC: Total Cholesterol; TG: triglycerides; HDL: High Density Lipoprotein; LDL: Low Density Lipoprotein

\section{Introduction}

Essential hypertension (EH) is an important worldwide public health issue which contributes to the burden of heart disease, stroke and kidney failure and premature mortality and disability. It disproportionately affects populations in low- and middle-income countries where health systems are weak. EH is a complex disorder resulting from genetic and environmental factors, as well as their interactions [1,2]. Approximately 20-60\% of the blood pressure variability in general population is heritable [3].

Human ADD1 gene, located on chromosome 4p16.3, encodes one of adducin subunits ( $\alpha$-adducin) [4]. Adducin modulates the surface expression of multiple transporters and ion pumps, and thus regulates cellular signal transduction and cytolemma ion transport [5]. Human and animal model studies have found that $A D D 1$ gene is a candidate gene for $\mathrm{EH}[5,6]$. One well-studied polymorphism in ADD1 gene is a missense mutation substituting thymine $(\mathrm{T})$ for guanine $(\mathrm{G})$ at position 614 of the $10^{\text {th }}$ exon, resulting in an expressed $A D D 1$ with Trp in place of the wild type Gly at amino acid 460 (Gly460Trp, rs4961), which was first described by Cusi et al. [7]. Then, a large number of studies were conducted on the association of Gly460Trp with EH. Consequently, ADD1 460Trp allele was reported to be a risk factor for EH in South European [7], Japanese [8] and Mongolian [9], inversely a protective factor in Scandinavian [10] and UK [11], but not associated with EH in Australian [12] and South Korean [13]. However, epidemiological studies have shown that the contribution of ADD1 Gly460Trp mutation to hypertension varies among different ethnic groups.

To convince the association of this mutation with $\mathrm{EH}$, several metaanalyses were recently performed from different angle [14-17]. Most of these analyses fail to provide evidence for the genetic association between $A D D 1$ Gly460Trp mutation and EH, but it is suggested that the 460Trp allele might be a risk factor of EH in Han Chinese population [17]. Up to now, the studies performed to explore the association of ADD1 Gly460Trp mutation with EH were mostly conducted in a small sample size. Therefore, aimed at clarifying the role of $A D D 1$ Gly460Trp in EH and exploring the interaction between this mutation and environmental factors on $\mathrm{EH}$, we conducted a case-control study in a large, homogeneous sample of Han Chinese population.

\section{Materials and Methods}

\section{Sample collection}

This study comprised 1020 cases (mean age, $58.5 \pm 6.4$ years;

*Corresponding author: Li-Na Zhang, School of Medicine, Ningbo University, Ningbo, Zhejiang 315211, 818 Fenghua road, Ningbo, Zhejiang 315211, PR China, Tel: 86-574-87609604; Fax: 86-574-87609604; E-mail: zhanglina@nbu.edu.cn

Received February 28, 2014; Accepted March 27, 2014; Published March 29 2014

Citation: Liu PP, Zhong QL, Yuan F, Zhong FD, Fan R, et al. (2014) Association between $A D D 1$ Gly460Trp Polymorphism and Essential Hypertension in Han Chinese. J Hypertens 3: 145. doi:10.4172/2167-1095.1000145

Copyright: () 2014 Liu PP, et al. This is an open-access article distributed under the terms of the Creative Commons Attribution License, which permits unrestricted use, distribution, and reproduction in any medium, provided the original author and source are credited. 
including 339 males and 681 females) and 1020 controls (58.3 \pm 6.5 years; 350 males and 670 females) collected from the community residents in Ningbo city of Zhejiang province, China. All individuals are Han Chinese living in Ningbo city for at least three generations, and their ages range from 35 to 70 years. Hypertensive patients were defined according to the golden standard [18]. All hypertensives have received antihypertensive medications for more than three months or have at least three consecutive records of systolic blood pressure (SBP) $>140$ $\mathrm{mmHg}$ and/or diastolic blood pressure (DBP) $>90 \mathrm{mmHg}$ (European Society of Hypertension-European Society of Cardiology Guidelines, 2003). Patients had SBP $<120 \mathrm{mmHg}$ and $\mathrm{DBP}<80 \mathrm{mmHg}$ and had no family history of hypertension in the first degree relatives were recruited as controls. None of the controls has received antihypertensive therapy. The gender and age of controls were well matched with EH cases. All the individuals don't have a history of diabetes mellitus, secondary hypertension, myocardial infarction, stroke, renal failure, drug abuse and other serious diseases. A calibrated mercury sphygmomanometer with appropriate adult cuff size was applied to measure blood pressures according to a standard protocol recommended by the American Heart Association [19]. Blood pressures were measured in supine position by two trained observers at an interval of at least 10 minutes. Blood samples were collected in $3.2 \%$ citrate sodium-treated tubes and then stored at -80 for DNA extraction. The study protocol was approved by the ethical committee of Ningbo University. The informed written consent was obtained from all subjects.

\section{Phenotypes collection}

Blood samples were obtained after a $12 \mathrm{~h}$ overnight fast from the antecubital vein using vacutainer tubes containing EDTA. Plasma levels of total cholesterol (TC), triglycerides (TG), high density lipoprotein (HDL) and low density lipoprotein (LDL) concentrations were enzymatically measured using CX7 biochemistry analyzer (Beckman, Fullerton, CA). Clinical information including body mass index (BMI), and weekly alcohol and cigarettes consumption were also obtained. In this study, who drank $\geq 70 \mathrm{~g}$ alcohol per week for more than 1 year was defined as individuals with alcohol abuse. Moreover, who smoked $\geq 70$ cigarettes per week for more than 1 year were defined as individuals with smoking habit.

\section{Single Nucleotide Polymorphism (SNP) genotyping}

Human genomic DNA was prepared from peripheral blood samples using the nucleic acid extraction automatic analyzer (Lab-Aid 820, Xiamen City, China). DNA was quantified using the PicoGreen ${ }^{\circledR}$ double strand DNA (dsDNA) Quantification Kit (Molecular Probes, Inc. Eugene, USA). Amplification was performed on the ABI GeneAmp ${ }^{\circledR}$ PCR System 9700 Dual 96-Well Sample Block Module (Applied Biosystems, Foster City, CA, USA) for the polymerase chain reaction (PCR), and the standard 96-well plates (Bioplastics, Landgraaf, Netherlands) was sealed with Cyclerseal Sealing Film (Platemax). PCR conditions included an initial enzyme heat-activation step of $95^{\circ} \mathrm{C}$ for $15 \mathrm{~min}$, followed by 35 amplification cycles (including $95^{\circ} \mathrm{C}$ for 20 $\mathrm{sec}, 59^{\circ} \mathrm{C}$ for $60 \mathrm{sec}$, and primer extension at $72^{\circ} \mathrm{C}$ for $30 \mathrm{sec}$ ), and a final extension for 7 minutes at $72^{\circ} \mathrm{C}$. PCR product for genotyping was performed on LightCycler ${ }^{\circledR} 480$ II Real-Time PCR (Roche Diagnostics Ltd., Rotkreuz, Switzerland) according to Melting Temperature shift method [20]. The PCR primers of SNP genotyping were described in Table S1.

\section{Statistical analysis}

Hardy-Weinberg equilibrium (HWE) was analyzed using the
Arlequin program (version 3.5) [21]. Statistical analyses were performed to investigate the association of $A D D 1$ Gly460Trp polymorphism and metabolic profile with EH using the PASW Statistics 18.0 software (SPSS, Inc., Somers, NY, USA). Either Pearson chi-square or Fisher exact test was used for the association of $\mathrm{EH}$ with categorical variables including gender, smoking, drinking, genotype, and allele frequencies. The odds ratio (OR) with $95 \%$ confidence interval $(95 \% \mathrm{CI})$ were calculated through an online tool (http://faculty.vassar.edu/lowry/ odds $2 \times 2 . h t m l)$. Two sample $t$-test was applied for the association of EH with continuous variables including age, BMI, TC, TG, HDL, and LDL. Multifactor dimensionality reduction (MDR) was used to identify and characterize interactions among ADD1 Gly460Trp polymorphism and the nongenetic factors, including BMI, serum HDL, LDL, TC, and TG level, as well as the distribution of smoking and drinking [22]. The software used for MDR is distributed in a JAVA platform with a graphical user interface and is freely available (http://www.epistasis. org/mdr.html). A two-sided p-value $<0.05$ was considered statistically significant.

\section{Results}

The baseline characteristics of all subjects are summarized in Table 1. Age, HDL, LDL, sex and smoking distribution showed no difference between hypertensive and control groups $(P>0.05)$. However, BMI, TC and TG were significantly higher in the hypertensive group than in the control group $(P<0.05)$. Additionally, drinking distribution was significantly different between hypertensive and control groups $(P<0.01)$, and the corresponding OR $(95 \% \mathrm{CI})$ was $2.43(1.82,3.26)$ (the data no showed in Table 1).

The genotypic and allelic frequency distributions of ADD1 Gly460Trp polymorphism were shown in Table 2. The genotype distribution was observed departure from the HWE in hypertensive cases $(P<0.01)$. However, the genotype distribution was significantly different between hypertensive and control groups, and the Gly460Trp polymorphism was found significantly associated with hypertension at allelic level $(P<0.01 ; \mathrm{OR}=0.85 ; 95 \% \mathrm{CI}=0.75-0.96)$. A breakdown association analysis by gender was also performed to explore the association between Gly460Trp polymorphism and EH (Table 2). Interestingly, the genotype distribution still deviated from the HWE in male hypertensive cases, but it was consistent with the HWE in female cases. No departure from the HWE was found in all control groups. The genotype distributions were still significantly different between hypertensive and control groups both in male $(P<0.01)$ and in female $(P<0.05)$. However, the Gly460Trp polymorphism was

\begin{tabular}{|c|c|c|c|}
\hline Variables & Hypertensive & Control & P value \\
\hline Number & 1020 & 1020 & N/A \\
\hline Gender (M/F) & $339 / 681$ & $350 / 670$ & 0.61 \\
\hline Age (years) & $58.5 \pm 6.4$ & $58.3 \pm 6.5$ & 0.58 \\
\hline $\mathrm{BMI}\left(\mathrm{kg} / \mathrm{m}^{2}\right)$ & $23.96 \pm 2.89$ & $22.94 \pm 2.77$ & $<0.01$ \\
\hline $\mathrm{TC}(\mathrm{mmol} / \mathrm{L})$ & $5.39 \pm 1.01$ & $5.28 \pm 1.05$ & 0.02 \\
\hline $\mathrm{TG}(\mathrm{mmol} / \mathrm{L})$ & $1.74 \pm 1.40$ & $1.52 \pm 0.86$ & $<0.01$ \\
\hline $\mathrm{HDL}(\mathrm{mmol} / \mathrm{L})$ & $1.68 \pm 0.47$ & $1.70 \pm 0.50$ & 0.57 \\
\hline $\mathrm{LDL}(\mathrm{mmol} / \mathrm{L})$ & $3.22 \pm 0.80$ & $3.16 \pm 0.83$ & 0.30 \\
\hline Smoking $(\mathrm{Y} / \mathrm{N})$ & $155 / 865$ & $148 / 872$ & 0.66 \\
\hline Drinking $(\mathrm{Y} / \mathrm{N})$ & $161 / 859$ & $73 / 947$ & $<0.01$ \\
\hline
\end{tabular}

BMI: body Mass Index; TC: Total Cholesterol; TG: Triglyceride; HDL: High Density Lipoprotein; LDL: Low Density Lipoprotein

Table 1: Characteristics of all subjects. 


\begin{tabular}{|c|c|c|c|c|c|c|c|c|c|c|c|}
\hline \multirow[t]{2}{*}{ Rs4961 } & \multicolumn{3}{|c|}{ Genotype frequencies } & \multirow[t]{2}{*}{$x^{2}$} & \multirow[t]{2}{*}{$P$} & \multirow[t]{2}{*}{ HWE } & \multicolumn{2}{|c|}{ Allele frequencies } & \multirow[t]{2}{*}{$x^{2}$} & \multirow[t]{2}{*}{$P$} & \multirow[t]{2}{*}{ OR $(95 \% \mathrm{Cl})$} \\
\hline & GG & GT & TT & & & & $\mathrm{T}$ & G & & & \\
\hline Case & 331 & 443 & 245 & \multirow{2}{*}{11.69} & \multirow{2}{*}{0.003} & $<0.01$ & 933 & 1105 & \multirow{2}{*}{6.94} & \multirow{2}{*}{0.008} & \multirow{2}{*}{$0.85(0.75,0.96)$} \\
\hline Control & 262 & 498 & 260 & & & 0.45 & 1018 & 1022 & & & \\
\hline M-case & 116 & 128 & 94 & \multirow{2}{*}{15.00} & \multirow{2}{*}{0.001} & $<0.01$ & 316 & 360 & \multirow{2}{*}{0.13} & \multirow{2}{*}{0.72} & \multirow{2}{*}{$0.96(0.78,1.19)$} \\
\hline M-control & 91 & 184 & 75 & & & 0.34 & 334 & 366 & & & \\
\hline F-case & 215 & 315 & 151 & \multirow{2}{*}{8.37} & \multirow{2}{*}{0.015} & 0.09 & 617 & 745 & \multirow{2}{*}{8.93} & \multirow{2}{*}{0.003} & \multirow{2}{*}{$0.79(0.68,0.92)$} \\
\hline F-control & 171 & 314 & 185 & & & 0.11 & 684 & 656 & & & \\
\hline
\end{tabular}

Table 2: Distribution of genotypic and allelic frequencies between case and control.

\begin{tabular}{|c|c|c|c|c|c|c|}
\hline Rs4961 & Dominant model (GT + TT vs. GG) & $P$ & OR $(95 \% \mathrm{Cl})$ & Recessive model (TT vs. GG + GT) & $P$ & OR $(95 \% \mathrm{Cl})$ \\
\hline Case & 688 vs. 331 & & & 245 vs. 774 & & \\
\hline Control & 758 vs. 262 & $<0.01$ & $0.72(0.59,0.87)$ & 260 vs. 760 & 0.47 & $0.93(0.76,1.13)$ \\
\hline M-case & 222 vs. 116 & & & 94 vs. 244 & & \\
\hline M-control & 259 vs. 91 & 0.02 & $0.67(0.48,0.93)$ & 75 vs. 275 & 0.06 & $1.41(0.99,2.00)$ \\
\hline F-case & 466 vs. 215 & & & 151 vs. 530 & & \\
\hline F-control & 499 vs. 171 & 0.02 & $0.74(0.59,0.94)$ & 185 vs. 485 & 0.02 & $0.75(0.58,0.96)$ \\
\hline
\end{tabular}

Table 3: Genetic analysis of ADD1 rs4961 mutation under dominant/recessive model.

\begin{tabular}{|l|c|c|c|c|}
\hline \multicolumn{1}{|c|}{ Best model } & Testing accuracy & Testing sensitivity & Testing odds ratio & Testing $\mathbf{x}^{\mathbf{2 t}}$ \\
\hline BMI & 0.60 & 0.46 & $2.69(0.95,7.64)$ & $3.57(p=0.06)$ \\
\hline BMI, drinking & 0.63 & 0.54 & $3.09(1.13,8.50)$ & $4.94(p=0.03)$ \\
\hline BMI, HDL, drinking & 0.64 & 0.51 & $3.77(1.31,10.88)$ & $6.33(p=0.01)$ \\
\hline BMI, HDL, drinking, rs4961 & 0.64 & 0.54 & $3.57(1.27,10.03)$ & $6.10(p=0.01)$ \\
\hline
\end{tabular}

Table 4: MDR analysis of gene-environment interaction.

observed significantly associated with hypertension at allelic level in female $(P<0.01 ; \mathrm{OR}=0.79 ; 95 \% \mathrm{CI}=0.68-0.92)$, but not in male $(P=0.72$; $\mathrm{OR}=0.96 ; 95 \% \mathrm{CI}=0.78-1.19)$.

Further genetic tests under the dominant and recessive inheritance models were performed for SNP rs4961 T allele, and the results of these tests are shown in Table 3. In the dominant model, a significant association between the rs4961 GT+TT genotype and EH was detected (hypertension cases versus control group: $P<0.01$; $\mathrm{OR}=0.72$; $95 \% \mathrm{CI}=0.59-0.87)$. However, in the recessive model, the significant association was only observed in female (hypertension cases versus control group: $P=0.02 ; \mathrm{OR}=0.75 ; 95 \% \mathrm{CI}=0.58-0.96$ ). Finally, $\mathrm{MDR}$ was used to analyze the interaction among Gly460Trp polymorphism and non-genetic risk factors for hypertension. The genotype of Gly460Trp polymorphism together with information about BMI, TC, TG, HDL, LDL, smoking, and drinking were input, consequently the software outputs the best model for "BMI, HDL, drinking, rs4961" with $10 / 10$ cross-validation consistency (Table 4).

\section{Discussion}

To evaluate the role of $A D D 1$ Gly460Trp and environmental factors in $\mathrm{EH}$ and clarify their interactions on $\mathrm{EH}$, we conducted a case-control study in a large, homogeneous sample of Han Chinese population. The gender and age were well matched between hypertensive and control groups. We found that BMI, TC, TG, and drinking were significantly associated with $\mathrm{EH}$, and they might be the risk factor for $\mathrm{EH}$. However, we did not find HDL, LDL and smoking were associated with EH. To our knowledge, this is the first study that a large-scale case-control study focusing on the association of ADD1 Gly460Trp with EH was performed in Chinese Han population, moreover, ADD1 Gly460Trp was found to be associated with $\mathrm{EH}$ in the present study. Additionally, Gly460Trp genotype distribution deviated from the HWE in hypertensive cases, which might opportunely clarify the association of Gly460Trp polymorphism with EH.
Adducin was implicated in the pathogenesis of EH by modulating $\mathrm{Na}^{+}-\mathrm{K}^{+}$-ATPase activity [23-25]. Evidence indicated that adducin might be a candidate protein to explain genetic alterations in ion transport associated with EH [24]. A previous study reported that hypertensive rat had an increased activity and expression of $\mathrm{Na}^{+}-\mathrm{K}^{+}$ pump [25]. Among the three adducin genes, ADD1 has received more attention than the other two. Several studies in humans demonstrated that the mutation of ADD1 gene may lead to the stimulation of the $\mathrm{Na}^{+}-\mathrm{K}^{+}$-ATPase activity in renal tubular cells, increased renal sodium reabsorption, and subsequently caused hypertension [26,27]. However, we found that $A D D 1460 \operatorname{Trp}$ allele might play a protective role in the pathogenesis of $\mathrm{EH}$. We speculated that ADD1 460Trp allele might influence the expression of $\alpha$-adducin which resulted in a reduced activity and expression of $\mathrm{Na}^{+}-\mathrm{K}^{+}$-pump, and consequently avoided $\mathrm{EH}$. Further studies are warranted to clarify the role of ADD1 Gly460Trp polymorphism in the pathogenesis of $\mathrm{EH}$.

Sexual dimorphism exists in the developmental origins of EH $[28,29]$. Males are reported to be more susceptible to hypertension than females [30]. Gender difference in the risk of hypertension was observed to be associated with altered expression of hormone receptors such as renal alpha2-adrenergic receptors [31] and angiotensin receptors [32]. In addition, $A D D 1$ Gly460Trp polymorphism was also observed to be associated with EH in female Caucasians [33]. After the breakdown association analysis stratified by gender, we found that ADD1 Gly460Trp was still associated with $\mathrm{EH}$ in females, but the association of ADD1 Gly460Trp with $\mathrm{EH}$ was not found in males. Additionally, the ADD1 460Trp allele was observed to be associated with $\mathrm{EH}$ in the dominant model, while we only found the association of ADD1 460Trp allele with EH in females in the recessive model. Our results verified the sexual dimorphism of $\mathrm{EH}$.

Moreover, epidemiological studies have documented environmental factors such as physical inactivity, obesity, high sodium and low potassium diet, and alcohol consumption are associated with 
Citation: Liu PP, Zhong QL, Yuan F, Zhong FD, Fan R, et al. (2014) Association between ADD1 Gly460Trp Polymorphism and Essential Hypertension in Han Chinese. J Hypertens 3: 145. doi:10.4172/2167-1095.1000145

Page 4 of 5

hypertension risk [34,35]. Disorders in the metabolism of HDL and TG play a key role in $\mathrm{EH}$ progression [36,37]. In the current study, we detected the association of EH with BMI, TC, TG and drinking, but not with HDL, LDL and smoking. However, the MDR analysis in this study demonstrated that BMI, HDL and drinking interacted with rs4961, which conjointly contributed to EH. Thereby, the present interaction analysis gave a little more information than the single genetic study.

In summary, the present study indicated that ADD1 Gly460Trp polymorphism was associated with $\mathrm{EH}$ in female Han Chinese. However, $\mathrm{EH}$ is a complex and polygenic disease, and ADD1 Gly460Trp polymorphism may play a tiny role in the pathogenesis of EH. In addition, our interaction analysis confirmed the interaction existed between genetic and non-genetic factors, suggesting that single genetic study is not enough for hypertension. In the future study, the interaction of genetic and environmental factors needs more attention to clarify the pathogenesis of this complex disease.

\section{Supporting Information}

Table S1: Primer sequences for ADD1 Gly460Trp polymorphism

\section{Acknowledgement}

The research was supported by the grants from National Natural Science Foundation of China (81373094), Natural Science Foundation of Ningbo City (2011A610037), and Key Program of Education Commission of Zhejiang Province (Z201017918)

\section{Conflicts of Interest}

There are no conflicts of interest.

\section{References}

1. GenSalt Collaborative Research Group (2007) GenSalt: rationale, design methods and baseline characteristics of study participants. J Hum Hypertens 21: $639-646$

2. Svetkey LP, Harris EL, Martin E, Vollmer WM, Meltesen GT, et al. (2011) Modulation of the BP response to diet by genes in the renin-angiotensin system and the adrenergic nervous system. Am J Hypertens 24: 209-217.

3. Kurtz TW, Spence MA (1993) Genetics of essential hypertension. Am J Med 94: 77-84.

4. Matsuoka Y, Li X, Bennett V (2000) Adducin: structure, function and regulation Cell Mol Life Sci 57: 884-895.

5. Tripodi G, Valtorta F, Torielli L, Chieregatti E, Salardi S, et al. (1996) Hypertensionassociated point mutations in the adducin alpha and beta subunits affect actin cytoskeleton and ion transport. J Clin Invest 97: 2815-2822.

6. Casari G1, Barlassina C, Cusi D, Zagato L, Muirhead R, et al. (1995) Association of the alpha-adducin locus with essential hypertension. Hypertension 25: 320-326.

7. Cusi D1, Barlassina C, Azzani T, Casari G, Citterio L, et al. (1997) Polymorphisms of alpha-adducin and salt sensitivity in patients with essential hypertension. Lancet 349: 1353-1357.

8. Tamaki S, Iwai N, Tsujita Y, Nakamura Y, Kinoshita M (1998) Polymorphism of alpha-adducin in Japanese patients with essential hypertension. Hypertens Res 21: 29-32.

9. Wang C, Sun G, Yan X, Ding Y (2007) Study of a-adducin and endothelial nitric oxide synthase gene polymorphism in patients with essential hypertension in mongulia population. Journal of Clinical Cardiology 23: 525-527.

10. Melander O, Bengtsson K, Orho-Melander M, Lindblad U, Forsblom C, et al. (2000) Role of the Gly460Trp polymorphism of the alpha-adducin gene in primary hypertension in Scandinavians. J Hum Hypertens 14: 43-46.

11. Clark CJ, Davies E, Anderson NH, Farmer R, Friel EC, et al. (2000) alphaadducin and angiotensin I-converting enzyme polymorphisms in essential hypertension. Hypertension 36: 990-994

12. Alam S, Liyou N, Davis D, Tresillian M, Johnson AG (2000) The 460Trp polymorphism of the human alpha-adducin gene is not associated with isolated systolic hypertension in elderly Australian Caucasians. J Hum Hypertens 14 199-203.

13. Shin MH, Chung EK, Kim HN, Park KS, Nam HS, et al. (2004) Alpha-adducin Gly460Trp polymorphism and essential hypertension in Korea. J Korean Med Sci 19: 812-814.

14. Liu K, Liu J, Huang Y, Liu Y, Lou Y, et al. (2010) Alpha-adducin Gly460Trp polymorphism and hypertension risk: a meta-analysis of 22 studies including 14303 cases and 15961 controls. PLoS One 5.

15. Niu W, Qi Y (2011) Association of $\hat{I} \pm$-adducin and G-protein $\hat{l}^{2} 3$ genetic polymorphisms with hypertension: a meta-analysis of Chinese populations. PLoS One 6: e17052.

16. Liu K, Liu Y, Liu J, Wang Z, Lou Y, et al. (2011) Ît-adducin Gly460Trp polymorphism and essential hypertension risk in Chinese: a meta-analysis. Hypertens Res 34: 389-399.

17. Li YY (2012) Î $\mathbf{\pm}-A d d u c i n$ Gly460Trp gene mutation and essential hypertension in a Chinese population: a meta-analysis including 10,960 subjects. PLoS One 7: e30214.

18. (2003) 2003 european society of hypertension-european society of cardiology guidelines for the management of arterial hypertension. J Hypertens 21:1011-1053

19. Perloff D, Grim C, Flack J, Frohlich ED, Hill M, et al. (1993) Human blood pressure determination by sphygmomanometry. Circulation 88: 2460-2470.

20. Yuan F, Xu J, Ji LD, Fei LJ, Liu PP, et al. (2012) [Application of Tm-shift genotyping method in genetic studies]. Yi Chuan 34: 1484-1490.

21. Excoffier L1, Lischer HE (2010) Arlequin suite ver 3.5: a new series of programs to perform population genetics analyses under Linux and Windows. Mol Ecol Resour 10: 564-567.

22. Motsinger AA, Ritchie MD (2006) The effect of reduction in cross-validation intervals on the performance of multifactor dimensionality reduction. Genet Epidemiol 30: 546-555.

23. Ferrandi M, Salardi S, Tripodi G, Barassi P, Rivera R, et al. (1999) Evidence for an interaction between adducin and $\mathrm{Na}(+)-\mathrm{K}(+)$-ATPase: relation to genetic hypertension. Am J Physiol 277: H1338-1349.

24. Bianchi G, Tripodi G, Casari G, Salardi S, Barber BR, et al. (1994) Two poin mutations within the adducin genes are involved in blood pressure variation. Proc Natl Acad Sci U S A 91: 3999-4003.

25. Ferrandi M, Tripodi G, Salardi S, Florio M, Modica R, et al. (1996) Renal Na,KATPase in genetic hypertension. Hypertension 28: 1018-1025.

26. Castejon AM, Alfieri AB, Hoffmann IS, Rathinavelu A, Cubeddu LX (2003) Alpha-adducin polymorphism, salt sensitivity, nitric oxide excretion, and cardiovascular risk factors in normotensive Hispanics. Am J Hypertens 16 1018-1024.

27. Staessen JA, Bianchi G (2005) Adducin and hypertension. Pharmacogenomics 6: 665-669.

28. Gilbert JS, Nijland MJ (2008) Sex differences in the developmental origins of hypertension and cardiorenal disease. Am J Physiol Regul Integr Comp Physio 295: R1941-1952.

29. Fisher ND, Ferri C, Bellini C, Santucci A, Gleason R, et al. (1997) Age gender, and non-modulation. A sexual dimorphism in essential hypertension. Hypertension 29: 980-985.

30. Dzudie A, Kengne AP, Muna WF, Ba H, Menanga A, et al. (2012) Prevalence, awareness, treatment and control of hypertension in a self-selected subSaharan African urban population: a cross-sectional study. BMJ Open 2.

31. Coatmellec-Taglioni G1, Dausse JP, Giudicelli Y, Ribière C (2002) Gender difference in diet-induced obesity hypertension: implication of renal alpha2adrenergic receptors. Am J Hypertens 15: 143-149.

32. Silva-Antonialli MM1, Tostes RC, Fernandes L, Fior-Chadi DR, Akamine EH, et al. (2004) A lower ratio of AT1/AT2 receptors of angiotensin II is found in female than in male spontaneously hypertensive rats. Cardiovasc Res 62: 587-593.

33. Wang JG, Staessen JA, Barlassina C, Fagard R, Kuznetsova T, et al. (2002) Association between hypertension and variation in the alpha- and beta-adducin genes in a white population. Kidney Int 62: 2152-2159.

34. Binder A (2007) A review of the genetics of essential hypertension. Curr Opin Cardiol 22: 176-184. 
Citation: Liu PP, Zhong QL, Yuan F, Zhong FD, Fan R, et al. (2014) Association between ADD1 Gly460Trp Polymorphism and Essential Hypertension in Han Chinese. J Hypertens 3: 145. doi:10.4172/2167-1095.1000145

Page 5 of 5

35. Whelton PK, He J, Appel LJ, Cutler JA, Havas S, et al. (2002) Primary prevention of hypertension: clinical and public health advisory from The National High Blood Pressure Education Program. JAMA 288: 1882-1888.

36. Zhang X, Giovannucci EL, Wu K, Smith-Warner SA, Fuchs CS, et al. (2012)
Magnesium intake, plasma C-peptide, and colorectal cancer incidence in US women: a 28-year follow-up study. Br J Cancer 106: 1335-1341.

37. Tohidi M, Hatami M, Hadaegh F, Azizi F (2012) Triglycerides and triglycerides to high-density lipoprotein cholesterol ratio are strong predictors of incident hypertension in Middle Eastern women. J Hum Hypertens 26: 525-532. 